\title{
Status and Suggestions of Multimodal Transport Development in Henan Province under the Belt and Road Initiative
}

\author{
Can Yang \\ School of Economics and Management, Beijing Jiaotong University, Beixiaguan, Beijing, China \\ 17120628@bjtu.edu.cn
}

Keywords: Belt and Road, Multimodal transport, Henan Province, Development proposals.

\begin{abstract}
The Belt and Road Initiative proposes new requirements for transportation methods and also brings new opportunities for the development of multimodal transport in Henan Province. Starting from the Belt and Road Initiative, this paper systematically sorts out the development status and existing problems of Henan multimodal transport, and proposes multimodal transport development proposals from the aspects of top-level planning, infrastructure, business entities, freight rate mechanism, information sharing and standardization construction.
\end{abstract}

\section{Introduction}

In 2013, Chinese President Xi Jinping proposed the national strategy of building the "New Silk Road Economic Belt" and the "21st Century Maritime Silk Road" and developing economic cooperation with countries along the route (Kun et al., 2017). The Belt and Road Initiative also puts forward new requirements for the development of logistics while promoting Chinese foreign trade. Single inefficient transportation methods can no longer meet the needs of inter-country connectivity, and multimodal transport is becoming more and more important. At present, Chinese multimodal transport is still in its infancy, and the implementation of the Belt and Road Initiative brings opportunities and challenges for the development of multimodal transport. In the strategic planning of the Belt and Road, Henan Province has a strategic position of inheriting the east and the west, coherently north and south, and has outstanding advantages in logistics, international trade, and cross-border e-commerce, which is an important hub for Chinese logistics channel. At the same time, Henan Province actively integrated into the construction of the Belt and Road, and successively issued policy documents such as the "China (Henan) Free Trade Pilot Zone Construction Implementation Plan” and the "Zhengzhou-Luxembourg Air Silk Road Construction Special Plan” to encourage the development of multimodal transport.

\section{Development Status}

\subsection{Good Development Trend}

After proposing the Belt and Road Initiative, Henan Province actively promoted the reform of 
the freight marketization process and introduced a number of policies to promote the development of multimodal transport. In 2016, the "Zhengzhou-Europe International Block train Intermodal Project" was selected for the first batch of multimodal transport demonstration projects. In 2017, the “Air Railway Intermodal Project” and "High-speed Rail Logistics Project” of Henan Province were selected for the second batch of multimodal transport demonstration projects. It can be seen that the development potential of multimodal transport in Henan Province is huge. In addition, the infrastructure construction in Henan Province has been continuously improved. By the end of 2017, the province's railway mileage reached 5,470 kilometers, of which 1,309 kilometers were highspeed rails, and the mileage of expressways was 6,523 kilometers. The construction of infrastructure has promoted the growth of cargo transportation. In 2017, the total cargo transportation volume of the province reached 2.29 billion tons, an increase of $11.7 \%$ over last year, ranking fifth in the country and showing a continuous growth trend in the next few years.

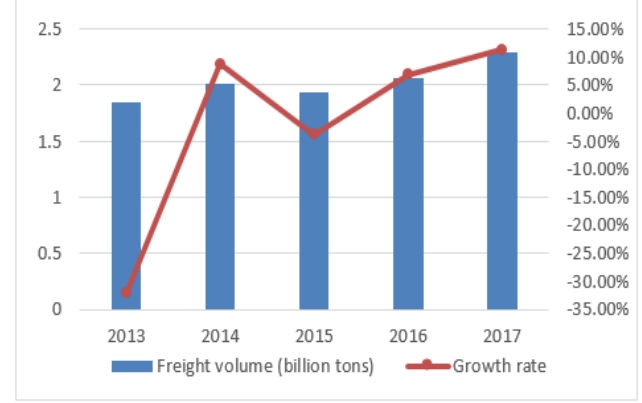

Figure 1 Freight volume of Henan Province.

\subsection{Rapid Development}

In recent years, Henan Province has continued to strengthen infrastructure construction, optimize the logistics channel network, and build a road-rail-air transport system integrating the "Land Silk Road” and the "Aerial Silk Road” under the background of the Belt and Road.

\subsubsection{Land Silk Road}

Zhengzhou-Europe International Block train is an important carrier for Henan Province to participate in the construction of the Land Silk Road. In 2013, Zhengzhou-Europe International Block train began operation, originated from Zhengzhou Railway Container Freight Center Station, and exited through Alashankou, Xinjiang, China, passing through Kazakhstan, Russia, Belarus, Poland and arrived in Hamburg, Germany, with a total length of 10,214 km and a running time of 11 to 15 days (Yangkun, 2015). As of July 2018, Zhengzhou-Europe International Block train had a total of 1,347 classes, with a cargo weight of 673,500 tons and a cargo value of 6.971 billion US dollars. It achieved a balanced round-trip operation of "every eight trips and eight return trips per week". The cargo radiation range of Zhengzhou-Europe International Block train continues to expand. In the territory, the source of the trains covers three-quarters of the provinces, and the collection radius reaches 1,500 kilometers, forming a domestic hub centered on Zhengzhou (Yuanhong, 2018). Outside the country, the trains cover the EU and Russia, forming a pattern with Hamburg as the hub, with Paris, Milan, Prague, Warsaw and Brest as the secondary collection centers. At the same time, the service form has been upgraded. Zhengzhou-Europe International Block train is the first train in the country to develop cold chain transportation. In the first half of 2018, it has transported 197 cases of refrigerators with a value of 25.68 million dollars. 


\subsubsection{Aerial Silk Road}

Relying on the Belt and Road strategy and cross-border e-commerce, in 2014, Henan Province opened a regular intercontinental freight route from Zhengzhou to Luxembourg, and built an Aerial Silk Road across Central Europe (Zengli et al., 2015). Since the opening of the intercontinental freight route, the flight has been increased from the initial two shifts per week to the current 18 shifts, covering European countries such as Luxembourg, Germany, the United Kingdom, and Belgium. In 2017, the freight volume of the Zhengzhou-Luxembourg intercontinental cargo route reached 147,000 tons, an increase of nearly $40 \%$ over last year. The international cargo routes, accumulated international cargo volume, and number of flights were at the top of Zhengzhou Airport, and the operation situation was good. Henan Province actively introduced Luxembourg strategic partners to innovate the truck service model. At present, there are more than 30 truck transport companies operating at Zhengzhou Airport, and the truck flight network covers more than 70 cities, greatly improving the collection and distribution capacity of Zhengzhou Airport.

Table 1 Multimodal transport system in Henan Province.

\begin{tabular}{|c|c|}
\hline Transport product & Transport routes \\
\hline Land silk road & $\begin{array}{c}\text { Zhengzhou- } \\
\text { Hamburg }\end{array}$ \\
\hline Aerial silk road & $\begin{array}{c}\text { Zhengzhou- } \\
\text { Luxembourg }\end{array}$ \\
\hline
\end{tabular}

\subsection{Continuous Innovation}

With the construction of the Henan Free Trade Zone and the development of cross-border ecommerce, trade between Henan and other countries has become more frequent. On the one hand, the multimodal transport cargo category has changed, and the main cargo has been transferred from grain and coal bulk cargo to high value-added products. For example, Zhengzhou-Europe International Block train mainly transports car accessories, construction machinery, electronic products and other goods. On the other hand, the service mode of multimodal transport continues to innovate. In 2017, the "single window" standard version of Henan was launched, and it has realized nine functions such as cargo declaration, enterprise qualification management, tax payment, statistical inquiry, processing trade and so on.

\section{Problems}

Under the Belt and Road Initiative, multimodal transport can not only optimize the transportation structure, but also achieve cost reduction and efficiency. At present, Henan's multimodal transport has achieved certain development, but multimodal transport accounts for a very low proportion of total freight, far behind Europe and the United States. Multimodal transport is in its infancy and there are still problems that must be solved.

\subsection{Infrastructure Lacks Effective Connectivity}

Henan Province has a variety of modes of transportation such as roads, railways, and aviation. However, there are problems with unsupported and unconnected infrastructure between various modes of transportation. The collection and distribution system is still not perfect, and the efficiency of distribution and distribution needs to be improved. The supporting road facilities for access to and from the station and the construction of connecting roads with high-speed railways 
need to be strengthened.

\subsection{Lack of Multimodal Transport Operators}

The multimodal transport operator refers to the person who enters into a multimodal transport contract with the consignor and is responsible for fulfilling or organizing the performance of the multimodal transport contract. This subject is conducive to clarify the intricate legal relationship in international multimodal transport. At present, the road freight volume accounts for about $90 \%$ of the total freight volume, so road transportation is the main transportation mode of Henan Province. And the freight forwarding mechanism is still not mature, and there is no powerful multimodal transport operator.

\subsection{Inflexible Multimodal Freight Rate Mechanism}

The pricing mechanism for different modes of transportation is different. The railway freight rate mechanism is not flexible enough. Although the railway bureau gives a discount on the maximum freight rate of no more than $30 \%$ in the management and no more than $50 \%$ across the bureau on the basis of the guidance price, the application for the downward policy of the enterprise requires multiple levels of approval, which makes it difficult to form a market competition advantage. While highway and air freight rates are relatively flexible and are based primarily on market conditions.

\subsection{Low Level of Information sharing}

At present, Henan Province has a local logistics information platform, and most transportation companies have corresponding business information systems, providing functions such as freight transportation, tracking and inquiry; China Railway Container Transport Company has a container management information system that provides functions such as tracking and statistical analysis; some customs and quarantine departments have also established online customs systems. In general, the level of multimodal transport information has improved, but information sharing has not been achieved between different information systems, resulting in inefficient business processing.

\subsection{Imperfect Standardization Construction}

There are still some shortcomings in the standardization construction in Henan Province, mainly including transportation specifications and transportation equipment. In terms of transportation equipment, the standard rate of trucks is relatively low, and there are many types of vehicles. It is difficult to achieve seamless integration with station facilities and railway transportation tools. In terms of transportation regulations, there is no standard intermodal service rules, and the systems for cargo handover, contract waybill, information sharing, liability division and insurance claims are not perfect.

\section{Suggestions}

\subsection{Optimize Multimodal Transport Top-level Planning}

Provide policy support for the development of multimodal transport in Henan Province. Relying on the important position in the strategy of the Belt and Road, Henan Province should actively strive for supporting policy support, such as transportation regulation policies, equipment standardization policies, incentive policies, supervision policies, subsidy policies, to provide policy support for the development of multimodal transport. 
Formulate the long-term development plan for multimodal transport in Henan Province. Zhengzhou-Europe International Block train and Zhengzhou-Luxembourg intercontinental freight route are the key points for Henan Province to participate in the construction of the Belt and Road, and have pointed out the direction for the development of multimodal transport in Henan Province. Henan Province should seize the opportunity of the Belt and Road construction, actively cooperate with powerful transportation companies in Europe and Asia Pacific, expand coverage areas and cooperation areas, and build an international integrated logistics hub.

\subsection{Strengthen the Construction of Infrastructure}

Optimize the multimodal transport network. In the territory, Henan Province should continue to improve the construction of road network, promote the connection between roads, railways, airports and ports, and smooth the domestic logistics channel. Outside the country, Henan Province needs to rely on its own location advantages to attract more freight companies with strong collection and distribution capabilities and wide coverage to open up and encrypt freight networks, expand the radiation range to Europe, Asia Pacific, Africa, and continuously expand the scale of operations.

Enhance the function of modern freight hubs. Accelerate the construction of Zhengzhou Airport and Zhengzhou International Port, renovate and upgrade existing station equipment and multimodal transport functional zones, and encourage the construction of specialized stations such as cold chains, commodity vehicles and chemicals. Improve the multimodal transport collection and distribution system, support the introduction of special railway lines in Zhengzhou Airport. At the same time, Henan Province needs to carry out international capital strategic cooperation, introduce well-known logistics enterprises at home and abroad, actively promote the integration and reorganization of international logistics integrators with global resources, and create a multimodal transport hub that is efficient and smooth.

\subsection{Cultivate the Main Body of Multimodal Transport Operations}

Reduce the entry barrier for multimodal transport operators. For enterprises in Henan Province that have obtained railway, road, air cargo transportation, car-free carrier, non-vessel shipping operation qualification or international freight forwarding, they can independently carry out the multimodal operation related to the expected main business, or jointly with other qualified enterprises to organize multimodal transport operations.

Enrich the composition of multimodal transport operators. Multimodal transport operators can be carriers of various modes, or car-free or non-vessel carriers. Henan Province should provide corresponding policy support. For multimodal transport operators, subsidized funds will be given in the early stage of operation, and they will be cultivated into transport enterprises with the ability to integrate transportation resources to provide one-stop services for cargo owners.

\subsection{Optimize the Multimodal Freight Rate Mechanism}

Accelerate the marketization process of freight prices. Give full play to the decisive role of the market in resource allocation, expand the scope of the railway freight price market adjustment, simplify the freight rate structure, and improve the freight rate system. At present, the transportation prices of railway containers, mineral building materials, less-than-truckload goods and metal products transported by whole vehicles are independently formulated by railway transport enterprises. In the future, Henan Province should continue to broaden the variety of goods that can be regulated by the market, and accelerate the marketization of railway freight prices.

Simplify approval process for tariff adjustments. The mechanism of layer-by-layer approval 
seriously affects the efficiency of railway freight price reform, which makes railway prices and market demand unsuitable. Therefore, the freight rate adjustment and approval process should be appropriately simplified, and a flexible railway freight price mechanism should be established to adapt to the rapid changes in market demand.

\subsection{Promote the Construction of Information}

Establish a unified multimodal transport information platform. Under the Belt and Road Initiative, Henan Province should develop information alliance cooperation mode with information as a link, and establish a multimodal transport information platform integrating cargo transportation, container management and customs. The information platform needs to provide customers with functions such as online ordering, logistics information inquiry, vehicle matching, electronic customs declaration, big data service, simplifying business processes and improving transportation efficiency.

Establish a platform credit evaluation system. Establish a credit rating model to evaluate the credit rating of users, and publicize information to praise the trustworthy and disciplinary believers. For users whose credit rating is lower than the minimum credit standard of the platform, temporary blockade is carried out to reduce platform trading risks and regulate market environment.

\subsection{Improve the Standardization of Multimodal Transport}

Promote the standardization of transportation facilities and equipment. Standardized transportation facilities and equipment are conducive to the seamless connection of different modes of transportation, which is crucial for the development of multimodal transport. For the carrying unit, Henan Province should actively promote international standard containers, implement preferential policies for some international standard container transport vehicles, such as reducing highway tolls, and invest funds to guide enterprises to use specialized containers, such as refrigerated containers and tank containers; For loading and unloading equipment, promote intelligent equipment such as hoisting, rolling, and translation of transportation modes to improve the level of automation of loading and unloading.

Develop standardized transportation rules. Henan Province should play a pioneering demonstration role, actively explore the standards of multimodal transport standards, and strengthen the system regulation of goods exchange, contract waybill, information sharing, responsibility division and insurance claims between different modes of transportation.

\section{References}

[1] Kun, Wang, Yongjian, Guo, Jianfei, Liu, and Huanhuan Zheng, 2017. Research on the Current Situation and Strategy of Multimodal Transport Development of the Logistics Industry_-In the Case of Henan Province, Innovation Science \& Technology. 17(12), pp.13-15.

[2] Yangkun, Wang, 2015. Status, Problems and Suggestions on Development of Sino-Europe Block Trains, Comprehensive Transportation. 37(S1), pp.70-75+89.

[3] Yuanhong, Zheng, 2018. Foreign experience of Zhengzhou Land port International Logistics Center construction, Journal of Henan Animal Husbandry Economics College. 31(03), pp.14-18.

[4] Zengli, Fang, Junxue, Ren, and Xianwei Li, 2015. Research on Multimodal Transport Problem in Zhengzhou Airport Economic Comprehensive Experimental Zone, Highways \& Automotive Applications. 34(03), pp.81-84. 